\title{
Synthesis of Methyl Esters from Silk Cotton Tree Seed Kernel Oil Using Dimethyl Carbonate and $\mathrm{KOH}$ Catalysis
}

\author{
Balaji Panchal 1*, Hazem M. Kalaji ${ }^{2}$, Sanjay Deshmukh ${ }^{1}$, Munish Sharma ${ }^{1}$, Waclaw Roman Strobel ${ }^{2}$ \\ ${ }^{1}$ Nurture Earth R and D Pvt. Ltd. MIT Campus, Beed Bypass Road, Aurangabad, INDIA \\ ${ }_{2}^{2}$ Institute of Technology and Life Sciences (ITP), Falenty, Al. Hrabska3, 05-090, Raszyn, POLAND
}

*Corresponding Author: panchalbalaji@yahoo.co.in

Citation: Panchal, B., Kalaji, H. M., Deshmukh, S., Sharma, M. and Strobel, W. R. (2018). Synthesis of Methyl Esters from Silk Cotton Tree Seed Kernel Oil Using Dimethyl Carbonate and KOH Catalysis. European Journal of Sustainable Development Research, 2(2), 20. https://doi.org/10.20897/ ejosdr/84899

Published: March 8, 2018

\begin{abstract}
Silk cotton seed kernel oil is given as a new source for methyl ester synthesis. Crude silk cotton oil was used as feedstock raw materials for methyl ester production using dimethyl carbonate as solvent and $\mathrm{KOH}$ catalysis. The maximum methyl esters yield produced as $97 \%$ with a kinematic viscosity $(4.25 \pm 0.25$ $\mathrm{mm}^{2} / \mathrm{sec}$ ) was reached at $80^{\circ} \mathrm{C}$ by boiling a mixture of dimethyl carbonate (DMC) and oil mole ratio as 8:1 with $1.5 \mathrm{wt} . \% \mathrm{KOH}$ catalyst (oil weight based) for $75 \mathrm{~min}$. The produced products were analyzed using gas chromatography-mass spectrometry to identify the methyl esters. The properties of the methyl esters from silk cottonseed kernel oil produced met the specifications of ASTM for methyl esters. The kinetics of the $\mathrm{KOH}$-catalyzed transesterification of diglyceride (DG) and triglyceride (TG) with DMC were studied at 40 to $90{ }^{\circ} \mathrm{C}$. We found that the activation energies for transesterification of diglycerides and triglycerides were 89.8 and $83.3 \mathrm{~kJ} / \mathrm{mol}$, respectively. The results showed that all the reaction variables studied had beneficial effects.
\end{abstract}

Keywords: silk cotton seeds, dimethyl carbonate, transesterification, kinetic study, activation energy

\section{INTRODUCTION}

The economic progress of any nation depends on a stable and relatively inexpensive supply of energy. A promising source of energy in the present-day world is biomass, from which biofuels, such as biodiesel are produced (Tukur and Ibrahim, 2015). The consumption of world petroleum reserves together with ever- increasing environmental concerns have stimulated the search for substitute renewable fuels that can realize the increasing demand for energy (Narasimharao and Wilson, 2007; Yang et al., 2014; Cai et al., 2015). Biodiesel is produced by a transesterification reaction in which triglycerides, vegetable oil or fat reacts with an alcohol in the presence of an alkaline catalyst ( $\mathrm{Li}$ et al., 2012). Biodiesel is produced by the transesterification of long-chain fatty acids obtained from edible oils, non-edible oil and animal fat with alcohols the presence of an appropriate catalyst (Ma et al., 2017).

Non-edible plant oils have been showed as promising crude oils for methyl ester production. The use of nonedible oils compared with edible oils is importantly higher in growing countries because of the tremendous call for edible oils for food, making edible oils far too high-cost to be used as fuel at present (Balat, 2011). Throughout the world, a large mass of non-edible oil plants is convenient (Balat, 2011).

Dimethyl carbonate (DMC) has a broad range of physical properties and chemical reactivities (Dawodu et al., 2014). DMC is synthesized from methanol and carbon dioxide, thereby making it an exactly green reagent with low toxicological and ecotoxicological properties. DMC has replaced methanol in biodiesel synthesis, in this 


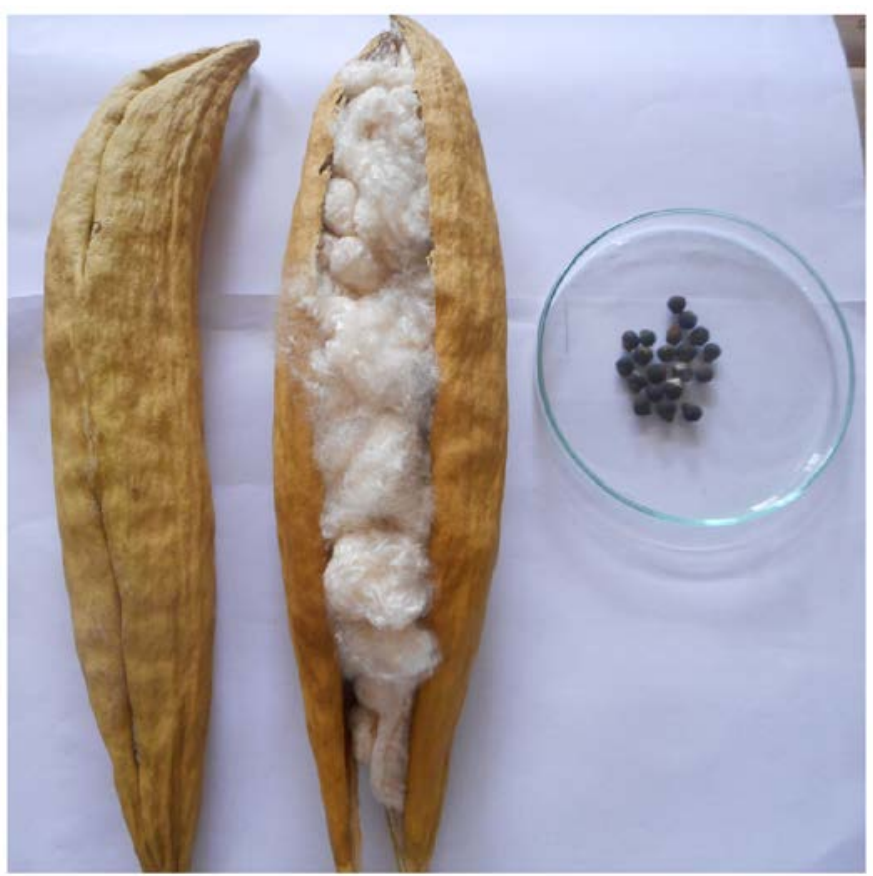

Figure 1. Fruit and seeds of the silk cotton seed tree

process, fatty acid methyl esters (FAMEs) are produced through the transesterification of soybean oil with DMC using potassium methoxide as a catalyst (Dawodu et al., 2014). DMC is a versatile mixture because it is an ecofriendly, non-toxic, and non-corrosive that exhibits low reactivity and better solvent properties (Panchal and Kalaji, 2017).

\section{Description of the Silk Cotton Tree and Seeds}

The silk cotton tree (Ceiba pentandra (L.) Gaertn) is found in tropical and subtropical regions in Asia, in India, Sri Lanka, Pakistan, Malaysia, Myanmar and Bangladesh (Shahin et al., 2016). Figure 1 shows the silk cotton tree fruit, the fruit with silk, and the seeds. The silk cotton tree is a fast-growing tree and becomes high-yielding within 4 to 5 years (Anigo et al., 2013). Yields increase for approximately eight years, and its economical lifespan is approximately 60 years. The silk cotton tree grows 6.0 to $7.0 \mathrm{~m}$ tall, may yield 330 to 400 fruits per year, giving 15 to $18 \mathrm{~kg}$ of fiber and $30 \mathrm{~kg}$ of seeds, with each fruit containing 200 seeds (Anigo et al., 2013). Silk cotton seed kernel oil is forest-based, non-edible seed oil (Kumar, 2014). A satisfactory fiber yield is $450 \mathrm{~kg} / \mathrm{ha}$, and a very high yield is $700 \mathrm{~kg} / \mathrm{ha}$ (Louppe et al., 2012). Silk cotton seed kernel oil is used as a down alternative to fill mattresses, pillows, upholstery, stuffed toys, such as teddy bears, and for insulation (Kumar, 2014).

\section{MATERIALS AND METHODS}

\section{Chemical Reagents}

All chemicals employed in the present research, dimethyl carbonate, potassium hydroxide, n-hexane, acetone, and chloroform, were analytical reagent grade chemicals procured from S.D. Fine-chem Limited of India.

\section{Seed Collection and Preparation of Powder}

Full-grown dried fruits of the silk cotton tree were collected from the Dr. B.A.M.Univesity, Aurangabad (MS), India. Seeds were separated from the fruits after cutting with a sharp steel knife, and only healthy seeds were selected. The seeds were cleaned and oven-dried at $40{ }^{\circ} \mathrm{C}$ for $24 \mathrm{~h}$ and then ground into uniform size, passed through an 80-mesh sieve, and stored in a glass jar before use.

\section{Extraction of Oil from Silk Cotton Seed Kernel Powder}

A total of $100 \mathrm{~g}$ of silk cotton seed kernel powder was extracted with $\mathrm{n}$-hexane at a ratio of 1:3 w/w (seed kernel powder: $\mathrm{n}$-hexane ratio). $100 \mathrm{~g}$ powder was soaked in $100 \mathrm{~g}$ of $\mathrm{n}$-hexane at room temperature for $15 \mathrm{~min}$. $200 \mathrm{~g}$ of $\mathrm{n}$-hexane was then added, and the developing mixture was agitated at $100 \mathrm{rpm}$ at $50{ }^{\circ} \mathrm{C}$ for $45 \mathrm{~min}$. Completing the extraction, the suspension was kept 30 min for settling, after settling $\mathrm{n}$-hexane with extracted oil was filtered through simple filter paper. The solvent containing oil from the filtrate was separated using a rotary 
vacuum evaporator. The remaining extracted oil in the sample flask was weighed after the completed process (Panchal et al., 2014). Experiments were conducted in three times.

\section{Optimization of Silk Cotton Seed Kernel Oil Methyl Ester Production}

The reaction variables employed through the optimization of silk cotton oil transesterification were the molar ratio of DMC to extracted oil (2:1 to 14:1), the $\mathrm{KOH}$ catalyst concentration ( 0.25 to $2.0 \%$ basis of oil weight w/w), the reaction temperature $\left(40\right.$ to $\left.90{ }^{\circ} \mathrm{C}\right)$, the agitation rate $(75$ to $375 \mathrm{rpm})$, and the reaction time (15 to $\left.90 \mathrm{~min}\right)$. The effect of each factor was estimated by varying one parameter while keeping the other parameters constant. After the reactions were stopped, the samples were cooled at room temperature and centrifuged at $500 \mathrm{rpm}$ for 10 min. Three layers were formed: the excess solvent phase, the methyl ester phase as the upper layer and glycerol carbonate as the lower layer phase. The methyl ester phase was separated, the excess solvent was evaporated at 30 ${ }^{\circ} \mathrm{C}$ in a rotary vacuum evaporator, and the methyl ester was purified by $0.5 \%$ Magnesol powder. The yield of purified methyl esters synthesized from silk cotton oil was then calculated. All experiments in this study were supervised in three times.

\section{Kinetic Experiments}

Experiments of kinetics were completed in a $1000 \mathrm{ml}$ 4-necked glass reactor with a stirrer connected the motor, a heating mantle, condenser, a thermometer and a sampling port. The molar ratio of DMC to oil and the catalyst quantity were confirmed for the optimal condition (8:1): $800 \mathrm{~g}$ of DMC and $100 \mathrm{~g}$ of oil contained the total volume of the reaction. The transesterification procedure, which examined the volume of withdrawn samples, yielded a maximum volume of $1 \%$ of the total reaction volume. Samples $0.5 \mathrm{ml}$ were withdrawn from the reaction mixture at systematic intervals, centrifuged at 10,000 rpm for $20 \mathrm{~min}$ and then filtered. A suspension with a known quantity of methyl heptadecanoate was prepared as an internal standard. Samples were prepared for gas chromatographymass spectrometry (GC-MS) analysis by adding $50 \mathrm{mg}$ of the sample and $0.25 \mathrm{ml}$ of the standard internal suspension $(5.082 \mathrm{mg} / \mathrm{ml})$ and diluting to $8 \mathrm{ml}$ with $\mathrm{n}$-heptane.

\section{GC-MS Analysis of Methyl Esters}

The completion of the transesterification reaction was estimated by thin layer chromatography. Methyl esters were determined by GC-MS on coupled to a mass spectrometer with the selective detector. Separation was attained on a DB-5MS capillary column ( $30 \mathrm{~m} \times 0.32 \mathrm{~mm}, 0.25 \mathrm{~mm}$ thickness). Helium was the carrier gas with a flow rate of $1.5 \mathrm{ml} / \mathrm{min}$. The temperature of the column was raised from $120-300{ }^{\circ} \mathrm{C}$ at $10{ }^{\circ} \mathrm{C} / \mathrm{min}$. A sample volume of $0.1 \mathrm{ml}$ of $\mathrm{HOB}$ in chloroform was pressed in split mode with 1:10 split ratio. The mass spectrometer was set to scan in the range of 50-550 m/z, with an electron impact mode of ionization (Panchal et al., 2016).

\section{Fuel Properties of Methyl Esters Synthesized from Silk Cotton Seed Kernel Oil}

The properties of the methyl esters synthesized from silk cotton seed kernel oil were determined according to ASTM specifications. Specific gravity at $25^{\circ} \mathrm{C}$, kinematic viscosity at $40{ }^{\circ} \mathrm{C}$, flash point, cloud point, pour point, copper strip corrosion at $60^{\circ} \mathrm{C}$ and acid value were determined in accordance with ASTM D5002, ASTM D445, ASTM D93, ASTM D2500, ASTM D97, ASTM D130 and ASTM D664 (Rengasamy et al., 2014).

\section{RESULT AND DISCUSSION}

\section{Analysis of the Properties of Extracted Silk Cotton Seed Kernel Oil}

The oil obtained from the silk cotton seed kernel is yellow dark in color and has a delicate odor. The extracted oil accommodated $24 \%$ crude fat. Crude silk cotton oil contains a rich percent of free fatty acids (Kumar, 2014). The expanse of the total monounsaturated, unsaturated and saturated carboxylic acids in the extracted oil was $52.89,35.11$ and $9.44 \%$, respectively. The silk cotton oil had a carboxylic acid profile of linoleic $(35.11 \%)$, oleic (29.69\%), palmitic $(23.20 \%)$ and lipid (5.68\%) acids (Ma and Hanna, 1999). The iodine value, which estimates the degree of unsaturation of oil, was $70.10 \mathrm{~g} \mathrm{I} / 100 \mathrm{~g}$ oil, and the saponification value was $158.28 \mathrm{mg} \mathrm{KOH} / \mathrm{g}$ oil, which is lower than the $94.98 \mathrm{~g} \mathrm{I} / 100 \mathrm{~g}$ oil and $183.0 \mathrm{mg} \mathrm{KOH} / \mathrm{g}$ oil values reported (Anigo et al., 2013).

\section{Effects of DMC and Oil Molar Ratio on the Methyl Ester Yield from Silk Cotton Seed Kernel Oil}

The effect of DMC and the oil molar ratio as the important parameters affecting methyl ester synthesis yields was explored by varying the molar ratio from $2: 1$ to $8: 1$, while fixing the reaction temperature and $\mathrm{KOH}$ concentration $0.9 \%$ (by oil wt) at $80{ }^{\circ} \mathrm{C}$, respectively, with agitation at $200 \mathrm{rpm}$. Seven dissimilar molar ratios $(2: 1$, 4:1, 6:1, 8:1, 10:1, 12:1 and 14:1) of DMC and oil were employed in the experiment. As shown in Figure 2, a DMC: oil molar ratio of 8:1 give the giant methyl ester synthesis yield as $97 \%$. When the DMC: oil molar ratio was 


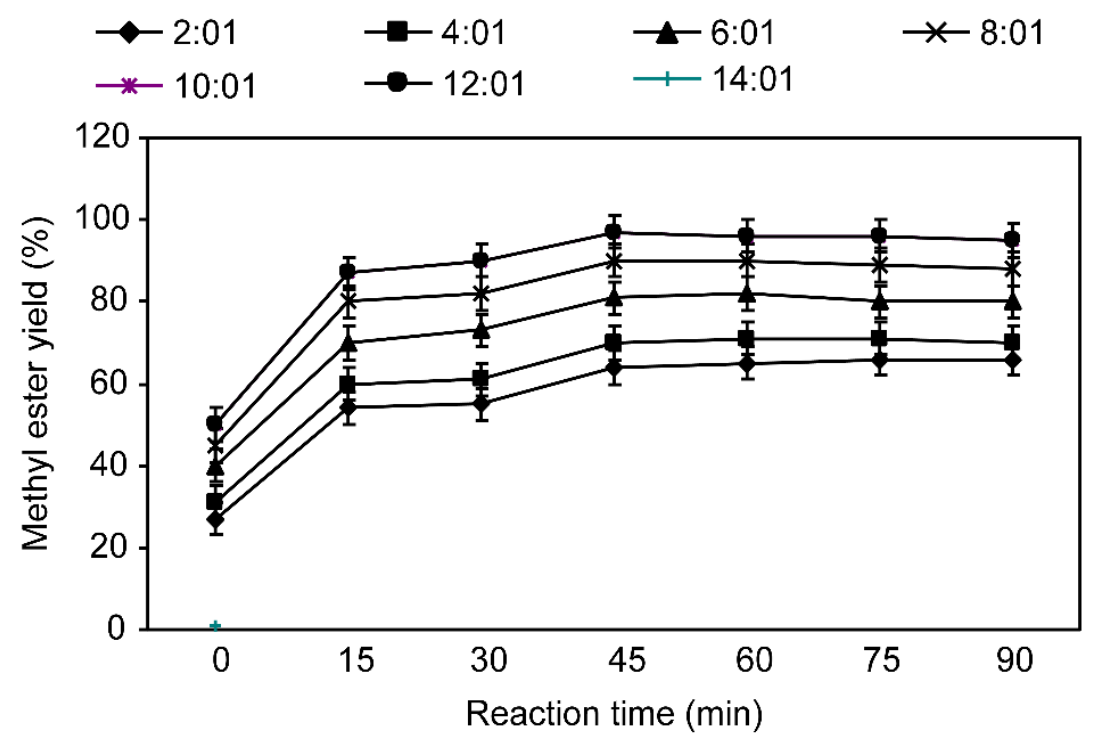

Figure 2. Effect of the DMC to oil molar ratio on silk cotton seed oil methyl ester yield. Reaction conditions: $1.5 \%$ catalyst concentration, $300 \mathrm{rpm}$ agitation speed at $80^{\circ} \mathrm{C}$ for $75 \mathrm{~min}$ and various DMC: silk cotton seed kernel oil molar ratios. Data represent the mean \pm standard deviation of triplicate observations

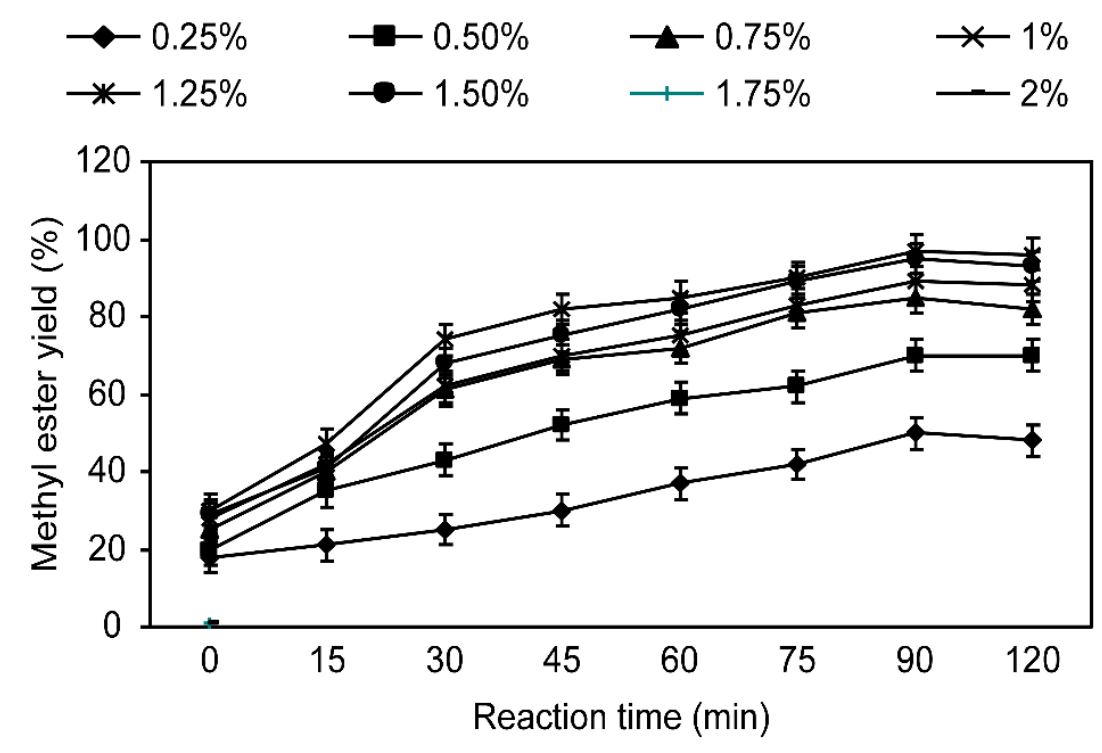

Figure 3. Effect of catalyst concentration on silk cotton seed oil methyl ester yield. Reaction conditions: molar ratio of DMC to silk cotton seed kernel oil (8:1), $300 \mathrm{rpm}$ agitation speed at $80{ }^{\circ} \mathrm{C}$ for $75 \mathrm{~min}$ and various catalyst concentrations. Data represent the mean \pm standard deviation of triplicate observations

enlarged further, e.g., from 8:1 to 10:1, the methyl ester content reduced somewhat. Precursory work found that the highest methyl ester synthesis yield reached $96.2 \%$ at refluxing temperatures for eight h with a DMC: oil molar ratio of 9:1 (Zhang et al., 2010). DMC: oil molar ratios of 4:1 and 6:1 might be assumed to have a diluting effect, yet these molar ratios can cause inadequate mixing of the reactants in the biphasic transesterification reaction procedure, which might show to lower methyl ester synthesis yields. The transesterification reaction between palm oil and DMC was optimized for the synthesis of methyl ester, and the optimal molar ratio was resolved to be 8:1 (Alia and Aziz, 2015). Other researcher investigated the highest biodiesel yield could reach $96.2 \%$ at refluxing temperature for eight $\mathrm{h}$ with a molar ratio of DMC and oil 9:1 (Zhang et al., 2010).

\section{Effect of Catalyst Concentration on Silk Cotton Seed Kernel Oil Methyl Ester Yield}

The catalyst concentration is the main variable that influences the methyl ester yield. $\mathrm{KOH}$ has demonstrated to be the most profitable catalyst due to a higher conversion rate of esters at a low temperature with a small reaction time (Panchal et al., 2015; Leung et al., 2010). The effect of KOH concentration on methyl ester synthesis was observed in the range of $0.5-2.0 \%$ ( $\mathrm{KOH} \%$ concerning oil weight). The reaction temperature and time were kept 


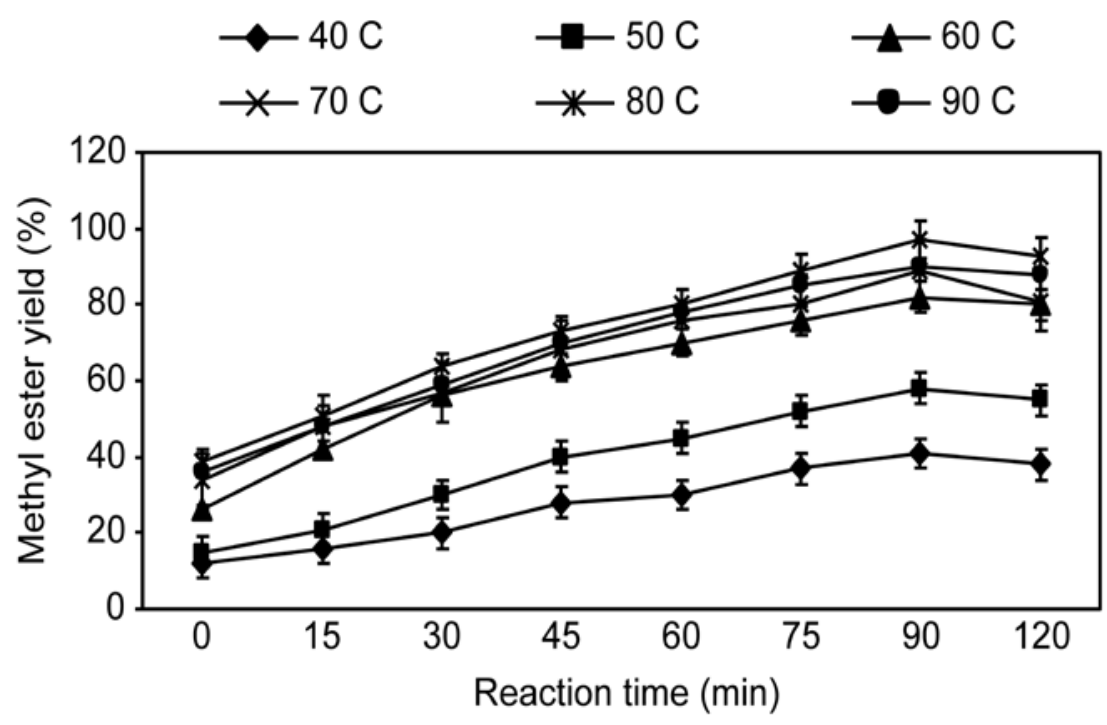

Figure 4. Effect of temperature on silk cotton seed oil methyl ester yield. Reaction conditions: molar ratio of DMC to silk cotton seed kernel oil (8:1), $300 \mathrm{rpm}$ agitation speed for $75 \mathrm{~min}, 1.5 \%$ catalyst concentrations and various reaction temperatures in ${ }^{\circ} \mathrm{C}$. Data represent the mean \pm standard deviation of triplicate observations

sustained at $80^{\circ} \mathrm{C}$ for $75 \mathrm{~min}$. The effect of the catalyst concentration on methyl ester synthesis yield is condensed in Figure 3 Increasing the catalyst concentration from $0.50-0.90 \%$ increased the methyl ester synthesis yield to 97\%. Increasing the concentration of catalyst has a positive effect on the yield of biodiesel (Panchal and Kalaji, 2017). Further increasing the catalyst concentration above $0.90 \%$ did not increase the methyl ester synthesis yield and alternatively led to a minute decrease in synthesis yield. Therefore, concentrations above $0.90 \%$ should be avoided. Thus, the optimal KOH catalyst concentration for methyl ester synthesis was $1.5 \%$. This decline is intelligible because the insertion of an intemperate quantity of alkaline catalyst conducts to the formation of an emulsion through increasing viscosity and complicates the convalescence of the methyl esters (Zhang et al., 2003). Sulistyo et al. (Sulistyo et al., 2008) investigated the leading results with a $\mathrm{KOH}$ concentration of $1.25 \%$ for the methanolysis of candlenut oil, which has a higher free fatty acid satisfied.

\section{Effect of Reaction Temperature on Silk Cotton Seed Kernel Oil Methyl Ester Yield}

The effect of reaction temperature on methyl ester yield during the transesterification of silk cotton oil was evaluated and using various temperatures $\left(40,50,60,70,80\right.$ and $\left.90^{\circ} \mathrm{C}\right)$. The DMC: oil molar ratio as 8:1 and $\mathrm{KOH}$ catalyst concentration as $1.5 \%$ (by oil weight) were held constant. Figure 4 shows the relationship between methyl ester yield and temperature of the reaction. The maximum methyl ester yield as $97 \%$ was achieved at $80{ }^{\circ} \mathrm{C}$ for 75 min, the methyl ester yield from silk cotton oil at 40, 50, 60, 70, and $90{ }^{\circ} \mathrm{C}$ was $41,58,82,89$ and $90 \%$, respectively. These results show that the methyl ester yield increased with increasing reaction temperature, with optimum yield as $97 \%$ at $80{ }^{\circ} \mathrm{C}$. Further increases in reaction temperature did not affect the methyl ester production yield, and a decrease was distinguished. Thus, the optimal reaction temperature for methyl ester production was defined as 80 ${ }^{\circ} \mathrm{C}$ from silk cotton oil. Rashid and Anwar (Rashid and Anwar, 2008) observed indistinguishable effects of temperature during the optimization of transesterification for producing methyl esters using rapeseed and Cynara cardunculus oils, respectively. Several researchers found that the increase in temperature influenced the reaction in a positive manner (Venkanna and Venkataraman, 2009).

\section{Effects of Agitation Speed on Silk Cotton Seed Kernel Oil Methyl Ester Yield}

The agitation speed appears to be of special significance for methyl ester synthesis. Panchal et al. (Panchal et al., 2012 ) reported that agitation speed was the important reason for biodiesel production. The methyl ester transesterification reaction obtain at the interface between oil and alcohol, and because these components are not miscible, strong mixing is required to increase the contact area between the immiscible phases (Singh and Fernando, 2006). The methyl ester yields at various agitation speeds during transesterification are presented in Figure 5. Methyl ester yield increased with increased mixing potency. Methyl ester synthesis was achieved at 80 ${ }^{\circ} \mathrm{C}$ and optimized with the highest achievable mixing level and an 8:1 DMC: oil molar ratio with an optimal KOH concentration of $1.5 \%$ (by weight of oil). At very low agitation speeds, such as $75 \mathrm{rpm}$, the methyl ester reaction did not reach completion. Increasing the stirring speed produced considerable increases in the methyl ester yield. The optimal methyl ester yield as $97 \%$ was noted after 75 min of reaction time at $300 \mathrm{rpm}$ agitation speed. In the current research work, no considerable increase in methyl ester yield was observed at 300 rpm. Rather, higher 


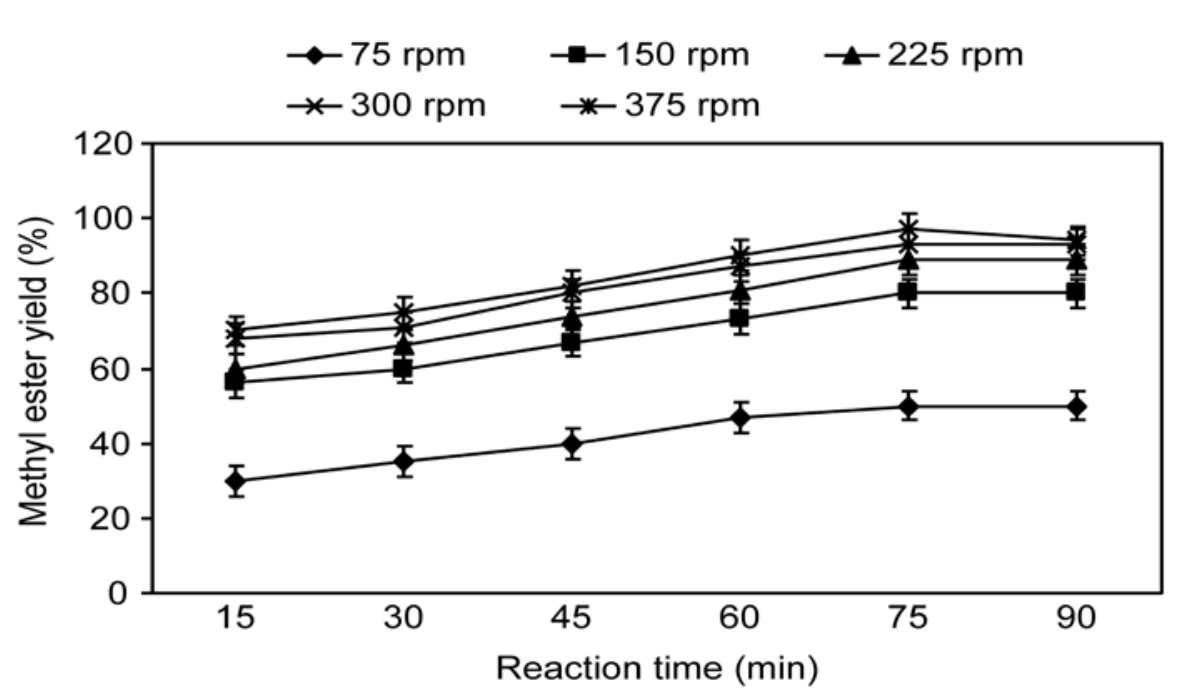

Figure 5. Effect of the agitation rate on silk cotton seed oil methyl ester yield. Reaction conditions: molar ratio of DMC to silk cotton seed kernel oil $(8: 1)$ at $80{ }^{\circ} \mathrm{C}$ for $75 \mathrm{~min}, 1.5 \%$ catalyst concentration and various agitation speeds. Data represent the mean \pm standard deviation of triplicate observations

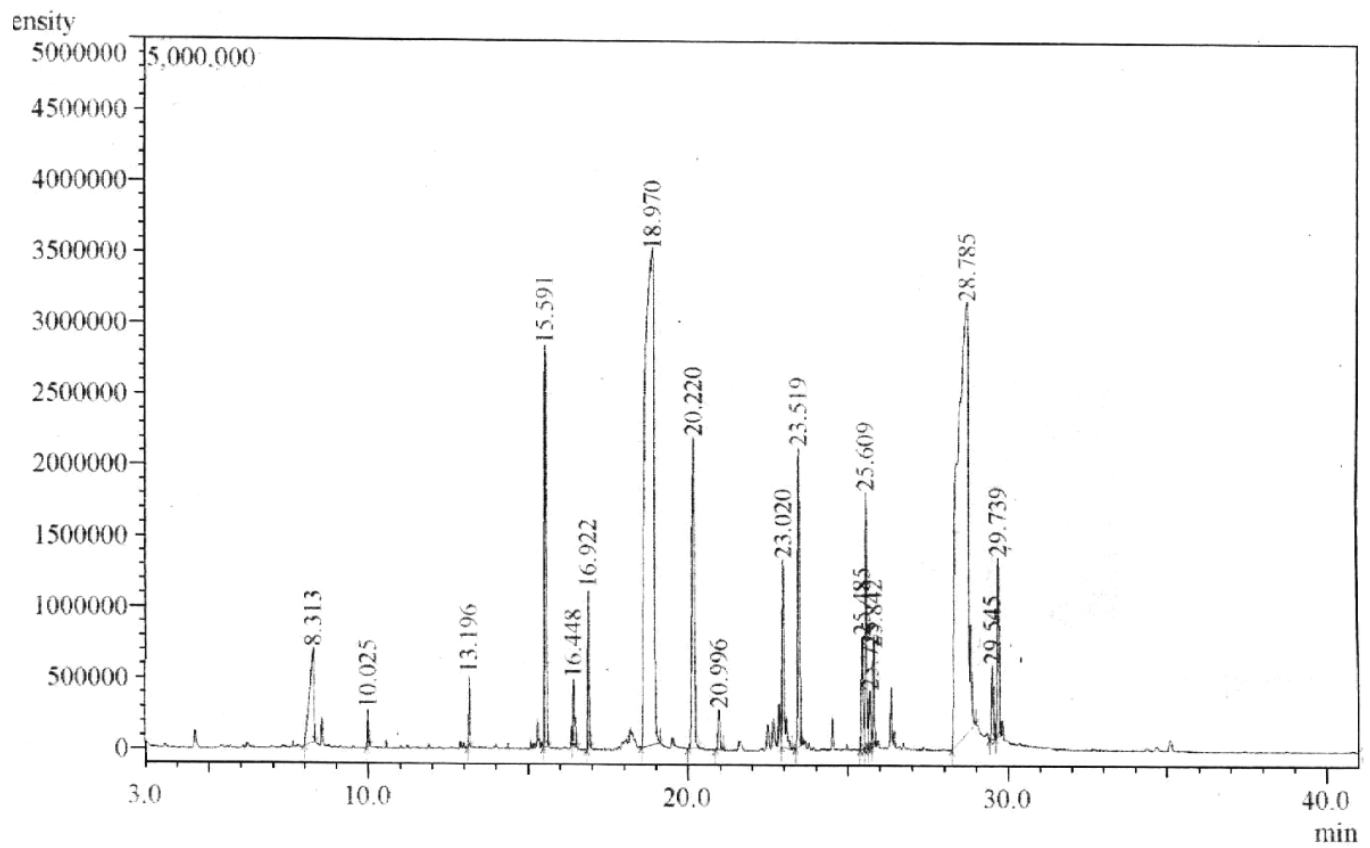

Figure 6. Chromatogram of methyl ester from silk cotton seed kernel oil

agitation speeds at $375 \mathrm{rpm}$ led to somewhat decreased methyl ester yields. Thus, the optimal agitation speed for methyl ester synthesis was $300 \mathrm{rpm}$. The small decrease in methyl ester yield at stirring rates at $650 \mathrm{rpm}$ volume might be associated with the attrition of particles and partly to the shearing of catalyst (Rashid et al., 2015). The kinetics of the transesterification of palm oil and DMC for methyl ester production has been investigated at agitation speeds of up to $200 \mathrm{rpm}$ (Sun et al., 2013).

\section{Analysis of Methyl Esters Synthesized from Silk Cotton Seed Kernel Oil}

Seven methyl ester derivatives were detected in the methyl esters synthesized from silk cotton oil; the largest were linoleic (34.11\%), oleic $(28.69 \%)$, palmitic $(22.48 \%)$, palmitoleic $(8.0 \%)$ alpha and gamma linoleic acid $(1.84 \%)$ and lipid (4.68\%) acids. Whole methyl ester content was $97 \%$, which may explain the high quality of the methyl esters synthesized from silk cotton oil, as shown in Figure 6. 
Table 1. Reaction rate constant for the transesterification of silk cotton seed kernel oil and DMC at different temperature

\begin{tabular}{ccc}
\hline Temperature $\left.\mathbf{~}^{\mathbf{o}} \mathbf{C}\right)$ & $\mathbf{k}\left(\mathbf{m i n}^{-\mathbf{1}}\right)$ & $\mathbf{R}^{\mathbf{2}}$ \\
\hline 40 & 0.00061 & 0.9663 \\
\hline 50 & 0.00072 & 0.9702 \\
\hline 60 & 0.00087 & 0.9795 \\
\hline 70 & 0.00119 & 0.9811 \\
\hline 80 & 0.00121 & 0.9908 \\
\hline 90 & 0.00123 & 0.9916 \\
\hline
\end{tabular}

\section{REACTION KINETICS}

\section{Kinetic Study Model}

The main purpose of the present research work was to distinguish the order of transesterification reactions at the DMC to oil molar ratio. Kinetic studies of the transesterification reaction methyl ester and glycerol dicarbonate were examined very small.

Three sequential steps occur stoichiometric reaction (Panchal et al., 2015; Shu et al., 2011).

$$
\begin{aligned}
T G+3 R O H & \rightleftharpoons C G+3 D M E \\
T G+R O H & \rightleftharpoons D G+D M E \\
D G+R O H & \rightleftharpoons M G+D M E \\
M G+R O H & \rightleftharpoons C G+D M E
\end{aligned}
$$

$\mathrm{DMC}$ was engaged in excess concerning oil to shift the reaction equilibrium toward the synthesis of methyl esters. Since small changes in the concentration of DMC during the reaction, the following rate equations were examined:

$$
\begin{gathered}
\mathrm{r}=-\frac{\mathrm{d}[\mathrm{TG}]}{\mathrm{dt}}=\mathrm{k}[\mathrm{TG}] \\
\ln [\mathrm{TG}]-\ln [\mathrm{TG}]=\mathrm{kt} \\
{[\mathrm{TG}]=[\mathrm{TG}]-\frac{[\mathrm{DMC}]-\mathrm{Sm}-\mathrm{BioD}}{3}}
\end{gathered}
$$

where $k$ is a rate constant, [TG] is the concentration of TG at the reaction time, and methyl ester is the concentration of methyl ester at the reaction time, which can get from the GC-MS analysis. When the constant rate $\mathrm{k}$ of the reaction at different temperatures was distinguished, the activation energy (Ea) of the reaction was calculated using the Arrhenius formula:

$$
\mathrm{E}_{\mathrm{a}}=-\mathrm{RT} \ln \left(\frac{\mathrm{K}}{\mathrm{A}}\right)
$$

where $A$ is the factor of frequency for the reaction, $R$ is the molar gas constant, and $T$ is the temperature.

$$
\ln (\mathrm{k})=\frac{\ln \mathrm{A}}{\mathrm{RT}}
$$

This equation (7) is linear; therefore, a plot of $\ln (\mathrm{k})$ vs. $1 / \mathrm{T}$ should produce a straight line with slope $-\mathrm{E} / \mathrm{RT}$.

\section{Determination of the Reaction Kinetics}

The transesterification reaction kinetics of DMC and oil were estimated at 40,50, 60, 70, 80 and $90{ }^{\circ} \mathrm{C}$, the molar ratio of DMC to oil was 8:1, and catalyst loading was 1.5\%. Methyl ester synthesis was slow during the initial stage of the transesterification reaction and later increased to reach equilibrium in $75 \mathrm{~min}$ due to changes in the methyl ester concentration. By fixing the results data at different temperatures using equation (4), the rate constant of reaction $(\mathrm{k})$ and its corresponding correlation coefficient are listed in Table 1. Ea was $75.2 \mathrm{~kJ}$ mol 1, and the pre-exponential factor was $1.09 \times 108 \mathrm{~min}^{-1}$.

\section{Properties of Silk Cotton Seed Kernel Oil Methyl Esters}

Methyl esters with the best properties were obtained using $\mathrm{KOH}$ as a catalyst in many investigated (Encinar et al., 2007; Gupta et al., 2007; Refaat et al., 2008; Demirbas, 2009). The character indications of the methyl ester synthesized from silk cotton seed oil are shown in Table 2. The kinematic viscosity of methyl ester is main for its 
Table 2. Properties of silk cotton tree seed oil methyl esters

\begin{tabular}{lcccc}
\hline Biodiesel properties & Units & Test methods & Silk cotton biodiesel & $\begin{array}{c}\text { Biodiesel standards } \\
\text { (ASTM D6751-02) }\end{array}$ \\
\hline Specific gravity at $25{ }^{\circ} \mathrm{C}$ & $\mathrm{gm} / \mathrm{cm} 3$ & ASTM D4052 & $0.847 \pm 0.12$ & Report \\
\hline Kinematic viscosity at $40{ }^{\circ} \mathrm{C}$ & $\mathrm{mm} / \mathrm{s}$ & ASTM D 445-06 & $4.25 \pm 0.25$ & $1.9-6.0$ \\
\hline Cloud point & ${ }^{\circ} \mathrm{C}$ & ASTM D 2500 & $6.00 \pm 0.20$ & Report \\
\hline Pour point & ${ }^{\circ} \mathrm{C}$ & ASTM D 97 & $4.00 \pm 0.01$ & Report \\
\hline Flash point, closed cup & ${ }^{\circ} \mathrm{C}$ & ASTM D 93 & $165 \pm 2.5$ & Min 130 \\
\hline Sulfur content & $\mathrm{wt} \%$ & ASTM D 5453 & 0.02 & 0.05 max \\
\hline Ash content & $\mathrm{wt} \%$ & ASTM D 874 & 0.01 & $0.02 \mathrm{max}$ \\
\hline Acid value & $\mathrm{mg} \mathrm{KOH} / \mathrm{g}$ & ASTM D 664-01 & $0.20 \pm 0.01$ & Max 0.5 \\
\hline Copper strip corrosion $\left(3 \mathrm{~h} \mathrm{at} 50{ }^{\circ} \mathrm{C}\right)$ & number & ASTM D 130-94 & $1 \mathrm{a}$ & Max. No. 3 \\
\hline Water and sediment & $\%$ vol & ASTM D130 & 0.01 & 0.05 max \\
\hline
\end{tabular}

pass through pipelines, injectors, nozzles and for fuel atomization in cylinders (Panchal et al., 2017). The kinematic viscosity of the silk cotton seed kernel oil methyl ester in the present research article was $4.25 \pm 0.25 \mathrm{~mm}^{2} / \mathrm{s}$ at 40 ${ }^{\circ} \mathrm{C}$. The kinematic viscosity of methyl ester is higher than that of diesel fuel, which is consistent with our detection of silk cotton oil methyl ester. In some cases, the kinematic viscosity of the fatty acids comprising a certain feedstock may affect the benefit of the resulting methyl esters (Knothe and Steidley, 2005). The specific gravity of the silk cotton seed oil methyl ester synthesized in the present research was $0.847 \pm 0.12 \mathrm{gm} / \mathrm{cm}^{3}$ at $25{ }^{\circ} \mathrm{C}$. The pour point is the main parameter corresponding to engine showing under cold weather conditions. The pour and cloud points of silk cotton seed oil methyl esters were $4.00 \pm 0.01$ and $6.00 \pm 0.20{ }^{\circ} \mathrm{C}$ respectively, production it a suitable fuel for use in cold conditions. The pour point is a measure of the biodiesel gelling temperature at which the fuel can no longer be pumped, and it is always lower than the cloud point (Bajpai and Tyagi, 2006). The acid value of the silk cotton seed oil methyl ester synthesized was $0.20 \pm 0.01 \mathrm{mg} \mathrm{KOH} / \mathrm{g}$. The flash point of silk cotton seed oil methyl ester was $165 \pm 2.5^{\circ} \mathrm{C}$. The flash point of methyl ester is higher than that of diesel $(67.58 \mathrm{C})$ (Meher et al., 2006; Nakpong and Wootthikanokkhan, 2010). Flash point was measured according to ASTM D93 (Fernando et al., 2007).

\section{CONCLUSIONS}

The present research article found the optimal reaction conditions for methyl ester synthesis from silk cotton seed kernel oil to be $1.5 \% \mathrm{KOH}$ catalyst, a DMC: oil molar ratio of $8: 1$, a reaction temperature of $80{ }^{\circ} \mathrm{C}$, and a stirring rate of $300 \mathrm{rpm}$. Transesterification reaction was almost completed in $75 \mathrm{~min}$, producing a 97\% methyl ester yield. The present investigation demonstrates that silk cotton seed kernel oil is a non-food feedstock that can be converted into methyl esters with very high yield $(97 \%)$ under an optimized set of transesterification reaction conditions. The results of the fuel characteristic tests on the silk cotton seed oil methyl esters indicated that it conformed to ASTM standard D6751-02. This synthesis process for methyl ester has a relatively low cost because of the silk cotton oil starting material and short reaction time, which we consider an economical fuel solution. The global human population is going to increase vastly; thus, more land may be needed to produce food for human consumption and animal feed, a problem that already exists in Asia.

\section{REFERENCES}

Ali, N. A. M. and Aziz, N. (2015). Optimization of DMC Transesterification Based Biodiesel Production. Advanced Materials Research, 1113, 370-375. https://doi.org/10.4028/www.scientific.net/AMR.1113.370

Anigo, K. M., Dauda, B. M. D., Sallau, A. B. and Chindo, I. E. (2013). Chemical Composition of Kapok (Ceibapentandra) Seed and Physicochemical Properties of its Oil. Nigerian Journal of Basic and Applied Sciences, 21, 105- 108. https:// doi.org/10.4314/njbas.v21i2.3

Bajpai, D. and Tyagi, V. K. (2006). Biodiesel: Source, Production, Composition, Properties and Its Benefits. Journal of Oleo Science, 55, 487-502. https://doi.org/10.5650/jos.55.487

Balat, M. (2011). Potential alternatives to edible oils for biodiesel production - A review of current work. Energy Conversion and Management, 52, 1479-1492. https://doi.org/10.1016/j.enconman.2010.10.011

Cai, Z., Wang, Y., Teng, Y., Chong, K., Wang, J., Zhang, J. and Yang, D. (2015). A two-step biodiesel production process from waste cooking oil via recycling crude glycerol esterification catalyzed by alkali catalyst. Fuel Processing Technology, 137, 186-93. https://doi.org/10.1016/j.fuproc.2015.04.017

Dawodu, F. A., Ayodele, O. O., Xin, J. and Zhang, S. (2014). Dimethyl carbonate mediated production of biodiesel at different reaction temperatures. Renewable Energy, 68, 581-587. https://doi.org/10.1016/j.renene.2014.02.036 
Demirbas, A. (2009). Progress and recent trends in biodiesel fuels. Energy Conversion and Management, 50(1), 14-34. https://doi.org/10.1016/j.enconman.2008.09.001

Encinar, J. M., Juan, F., Gonzalez, J. F., Rodriguez-Reinares, A. (2007). Ethanolysis of used frying oil. Biodiesel preparation and characterization. Fuel Processing Technology, 88(5), 513-522. https://doi.org/10.1016/j.fuproc.2007.01.002

Fernando, S., Karra, P., Hernandez, P. R. and Jha, S. K. (2007). Effect of incompletely converted soybean oil on biodiesel quality. Energy, 32(5), 844-851. https:// doi.org/10.1016/j.energy.2006.06.019

Gupta, A., Sharma, S. K. and Pal Toor, A. (2007). An empirical correlation in predicting the viscosity of refined vegetable oils. Indian Journal of Chemical Technology, 14, 642-645.

Knothe, G. and Steidley, K. R. (2005). Kinematic viscosity of biodiesel fuel components and related compounds. Influence of compound structure and comparison to petrodiesel fuel components. Fuel, 84, 1059-1065. https://doi.org/10.1016/j.fuel.2005.01.016

Kumar, R. and Titus, J. (2014). Experimental Investigation on Performance and Emission Analysis of CI Engine Fuelled with Methyl Ester of Silk Cotton Oil and Various Diesel Blends. International Journal of Mechanical Engineering and Robotics Research, 3(4), 195-205.

Li, Y., Guo, H., Zhu, Z., Feng, Y. and Liu, S. (2012). Ethylene Glycol Monomethyl Ether Cottonseed Oil Monoester: Properties Evaluation as Biofuel. International Journal of Green Energy, 9, 376-387. https://doi.org/10.1080/15435075.2011.621483

Leung, D. Y. C., Wu, X. and Leung, M. K. H. (2010). A review on biodiesel production using catalyzed transesterification. Applied Energy, 87, 1083-1095. https://doi.org/10.1016/j.apenergy.2009.10.006

Louppe, D., Oteng-Amoako, A. A. and Brink, M. (2012). Evaluation of Phytochemicals and Antioxidant Activities of Ceiba pentandra (Kapok) Seed Oil. Journal of Bioanalysis \& Biomedicine, 4, 68-73. https://doi.org/10.4172/1948-593X.1000065

Ma, F. and Hanna, M. A. (1999). Biodiesel production: A review. Bioresource Technology, 70, 1-15. https://doi.org/10.1016/S0960-8524(99)00025-5

Ma, Y., Wang, Q., Sun, X., Wu, C. and Gao, Z. (2017). Kinetics studies of biodiesel production from waste cooking oil using $\mathrm{FeCl}_{3}$-modified resin as heterogeneous catalyst. Renewable Energy, 107, 522-530. https://doi.org/10.1016/j.renene.2017.02.007

Meher, L. C., Sagar, D. V. and Naik, S. N. (2006). Technical aspects of biodiesel production by transesterificationa review. Renewable and Sustainable Energy Reviews, 10, 248-268. https://doi.org/10.1016/j.rser.2004.09.002

Nakpong, P. and Wootthikanokkhan, S. (2010). Optimization of Biodiesel Production from Jatropha curcas L. Oil via Alkali-Catalyzed Methanolysis. Journal of Sustainable Energy \& Environment, 1, 105-109.

Narasimharao, K., Lee, A. and Wilson, K. (2007). Catalysts in Production of Biodiesel: A Review. Journal of Biobased Materials and Bioenergy, 1, 19-30.

Panchal, B. M., Dhoot, S., Deshmukh, S., Sharma, M. and Kachole, M. (2012). Production of DMC-BioD from Pongamia pinnata seed oil using dimethyl carbonate. Fuel, 109, 201-205. https://doi.org/10.1016/j.fuel.2012.12.052

Panchal, B., Deshmukh, S. and Sharma, M. (2014). Optimization of Oil Extraction and Characterization from Tamarindus Indica Linn Seed Oil. International Journal of Oil, Gas and Coal Engineering, 2, 1-6. https://doi.org/10.11648/j.ogce.20140201.11

Panchal, B. M., Deshmukh, S. A. and Sharma, M.R. (2015). Kinetic and effective production of DMC-Sm-BioDs from Sapindus mukorossi seed kernel powder using dimethyl carbonate with $\mathrm{KOH}-$ Folch mixture solution as a catalyst. Biofuels, 6, 305-312. https://doi.org/10.1080/17597269.2015.1106929

Panchal, B. M., Deshmukh, S.A. and Sharma, M. R. (2016). Biodiesel from Thevetia peruviana Seed Oil with Dimethyl Carbonate Using as an Active Catalyst Potassium-Methoxide. Sains Malaysiana, 45(10), 1461-1468.

Panchal, B. M. and Kalaji, H. M. (2017). Synthesis and use of a catalyst in the production of biodiesel from Pongamia pinnata seed oil with dimethyl carbonate. International Journal of Green Energy, 14, 624-631. https://doi.org/10.1080/15435075.2017.1313739

Rashid, U. and Anwar, F. (2008). Production of biodiesel through optimized alkaline-catalyzed transesterification of rapeseed oil. Fuel, 87, 265-273. https://doi.org/10.1016/j.fuel.2007.05.003

Rashid, U., Anwar, F., Yunus, R., Al-Muhtaseb, A. H. (2015). Transesterification for Biodiesel Production Using Thespesia Populnea Seed Oil: An Optimization Study. International Journal of Green Energy, 12, 479-484. https://doi.org/10.1080/15435075.2013.853177

Panchal, B. M., Deshmukh, S. A. and Sharma, M. R. (2017). Production and kinetic transesterification of biodiesel from yellow grease with dimethyl carbonate using methanesulfonic acid as a catalyst. Environmental Progress \& Sustainable Energy, 36(3), 802-807. https:// doi.org/10.1002/ep.12559 
Refaat, A. A., Attia, N. K., Sibak, H. A., El Sheltawy, S. T. and El Diwani, G. I. (2008). Production optimization and quality assessment of biodiesel from waste vegetable oil. International Journal of Environmental Science \& Technology, 5(1), 75-82. https://doi.org/10.1007/BF03325999

Rengasamy, M., Anbalagan, K. and Mohanraj, S. (2014). Biodiesel Production from Pongamia pinnata Oil using Synthesized Iron Nanocatalyst. International Journal of Chem Tech Research, 6, 4511-4516.

Shahin, A., Shahal, A., Lisa, S. A. and Tanzima, P. (2016). Analysis of Fatty acid and Determination of Total Protein, Alkaloid, Saponin, Flavonoid of Bangladeshi Bombax ceiba Linn Leaves and Seeds. Indian Journal of Pharmaceutical and Biological Research (IJPBR), 4(4), 23-28.

Shu, Q., Gao, J., Liao, Y. and Wang, J. (2011). Reaction Kinetics of Biodiesel Synthesis from Waste Oil Using a Carbon-based Solid Acid Catalyst. Chinese Journal of Chemical Engineering, 19(1), 163-168. https://doi.org/10.1016/S1004-9541(09)60193-2

Singh, A. K. and Fernando, S. D. (2006). Base Catalyzed Fast-Transesterification of Soybean Oil Using Ultrasonication. In American Society of Agricultural Engineers, Annual Meeting, Portland, Oregon, USA. https://doi.org/10.13031/2013.21551

Sulistyo, H., Rahayu, S. S. and Winoto, G. (2008). Biodiesel Production from High Iodine Number Candlenut Oil. World Academy of Science, Engineering and Technology, 48, 485-488.

Sun, S., Zhang, L., Meng, X. and Xin, Z. (2013). Kinetic study on lipase catalyzed trans-esterification of palm oil and dimethyl carbonate for biodiesel production. Journal of Renewable and Sustainable Energy, 5, 033127. https://doi.org/10.1063/1.4803744

Tukur, Y. and Ibrahim, H. (2015). Transesterification of Kapok Oil Using Calcium Oxide Catalyst: Methyl Esters Yield with Catalyst Loading. International Journal of Scientific \& Technology Research, 4, 359-361.

Venkanna, B. K. and Venkataraman, R. C. (2009). Biodiesel production and optimization from Calophyllum inophyllum linn oil (honne oil) - A three stage method. Bioresource Technology, 100(21), 5122-5125. https://doi.org/10.1016/j.biortech.2009.05.023

Yang, S., Qing, L., Yang, G., Longyu, Z. and Ziduo, L. (2014). Biodiesel production from swine manure via housefly larvae (Musca domestica L.). Renewable Energy, 66, 222-227. https://doi.org/10.1016/j.renene.2013.11.076

Zhang, L., Sheng, B., Xin, Z., Liu, Q. and Sun, S. (2010). Kinetics of transesterification of palm oil and dimethyl carbonate for biodiesel production at the catalysis of heterogeneous base catalyst. Bioresource Technology, 101(21), 8144-8150. https://doi.org/10.1016/j.biortech.2010.05.069

Zhang, Y., Dubé, M. A., Mclean, D. D. and Kates, M. (2003). Biodiesel production from waste cooking oil: 2. Economic assessment and sensitivity analysis. Bioresource Technology, 90(3), 229-240. https://doi.org/10.1016/S0960-8524(03)00150-0 